\title{
Using technology to bring online convenience to offline shopping
}

\section{Marnik G. Dekimpe ${ }^{1,2} \cdot$ Inge Geyskens $^{1}$ (D) Katrijn Gielens ${ }^{3}$}

Published online: 5 December 2019

(C) The Author(s) 2019

\begin{abstract}
In spite of the growing success of the online channel, brick-and-mortar stores can continue to play a pivotal role in consumers' shopper journey. We discuss how technology can be a key enabler by allowing physical stores to offer the level of convenience consumers have become used to in the online channel.
\end{abstract}

Keywords Retailing $\cdot$ Technology $\cdot$ Convenience $\cdot$ Brick-and-mortar $\cdot$ Online

\section{Introduction}

As consumer spending is increasingly migrating from brick-and-mortar stores to online alternatives, the online channel has emerged as the only channel that has consistently experienced double-digit growth over the last decade. Moreover, the number of categories where online captures a substantial part of total category revenues is rapidly expanding. Table 1 illustrates how categories are leaving the store floor in favor of online channels.

This evolution does not bode well for brick-and-mortar stores, whose samestore sales have been declining for years. Chains as diverse as Family Dollar, Gap,

Marnik G. Dekimpe

m.g.dekimpe@tilburguniversity.edu

Inge Geyskens

i.geyskens@tilburguniversity.edu

Katrijn Gielens

katrijn_gielens@unc.edu

1 Department of Marketing, Marketing at Tilburg University, Warandelaan 5, 5037 AB Tilburg, the Netherlands

2 KU Leuven, Leuven, Belgium

3 University of North Carolina at Chapel Hill, Campus Box 3490, McColl Building, Chapel Hill, NC 27599-3490, USA 
Table 1 Online share of total US category sales and estimated 2017-2021 CAGR

\begin{tabular}{lll}
\hline Category & $\begin{array}{l}2016 \text { online } \\
\text { share }(\%)\end{array}$ & $\begin{array}{l}2017-2021 \\
\text { CAGR }(\%)\end{array}$ \\
\hline Baby & 44 & 12 \\
Books & 44 & 12 \\
Cosmetics & 15 & 13 \\
Electronics & 31 & 12 \\
Furniture & 15 & 16 \\
Grocery & 2 & 24 \\
Music/video & 65 & 11 \\
Office supplies & 27 & 7 \\
Pet & 10 & 16 \\
Sporting goods & 14 & 8 \\
Toys & 30 & 15 \\
\hline
\end{tabular}

Source: PlanetRetail RNG (2019)

Gymboree, Kmart, Lifeway, Payless, Performance Bicycle, Sears, Shopko, and Walgreens have each closed (or announced to close) more than 100 of their US stores in 2019. In total, more than 8000 stores are expected to close in 2019, even though US retailers already reduced their combined store space with a record 155 million square feet in 2018 (Business Insider 2019).

In spite of these ominous figures, doom thinking that predicts the death of the physical store seems premature. Indeed, more than $90 \%$ of all purchases (including online purchases) still involve, for one or more stages of the purchase funnel, a physical store (PlanetRetail 2016). These physical touchpoints offer brick-andmortar retailers opportunities to withstand further erosion, or to recapture lost ground. However, retailers should realize that online shopping has fundamentally changed consumers' expectations about physical shopping: they now expect the same convenience in the physical as in the digital channel. Meeting these expectations may not be easy, as online offers consumers ease of navigation (through search engines and personalized filters), individual-tailored suggestions (through recommendation systems), and easy price comparisons (through comparison algorithms). To do so, retailers have to adopt recent technological breakthroughs to create an equally frictionless shopping environment in-store.

Below, we identify some of the most promising shopper-facing technologies that brick-and-mortar retailers can use to actively manage customer touchpoints and deliver high levels of convenience across the various stages of the shopper journey. Following Seiders et al. (2000), we distinguish between different types of shopping convenience that mirror the shopper journey: search convenience (the ease of identifying desired products), possession convenience (the ease of obtaining desired products from a retailer), and transaction convenience (the ease of effecting transactions with the retailer). While some of these shopper-journey activities uniquely take place inside the physical store, others are integrated within the online channel. 


\section{Search convenience: product discovery and selection}

Retailers increasingly implement beacon technology to track customers' in-store movements and help them find their way around the store. Kroger's app, for example, simplifies the shopping experience by displaying the exact aisle location of products, while Target uses beacon technology to dynamically re-sort shopping lists as the user moves through the store, similar to how smartphone maps re-route users when veering off course. Other retailers use robots to demonstrate new products (e.g., Media Markt's Rotterdam store; Lowe's Lowbot), or offer hands-free shopping carts that guide shoppers through the store (e.g., 7Fresh).

While virtual reality is a big trend in e-commerce, augmented/mixed reality - which integrates physical and virtual experiences - offers more potential for physical stores. Sephora, for example, offers "magic mirrors" in its stores to help consumers visualize different make-up treatments. As another example, Oaks Labs developed an RFIDenabled interactive touch-screen mirror that recognizes all items a consumer takes into a fitting room, and then acts as a (digital) sales assistant enabling consumers to request other sizes, colors, or matching items from a (human) salesperson. These smart mirrors create frictionless experiences in the fitting room, the place with the highest in-store conversion potential for apparel retailers, yet also the place of highest in-store dissatisfaction.

\section{Possession convenience: personalization and fulfilment}

Brick-and-mortar stores have long struggled to replicate the personalization level achieved online. Traditionally, they could only analyze, ex post, customers' purchase data. Now, they can track real-time shopper behavior via consumers' smartphones, and assess which products shoppers were interested in, but decided not to buy. This considerably reduces their information disadvantage relative to online retailers who rely on consumer-browsing data. In combination with smart shelf labels, this new source of real-time information allows retailers to offer tailored recommendations and personalized discounts during the critical First Moment of Truth. Taking it one step further, retailers like Safeway are exploring how they can move towards individualized pricing, whereby consumers in the same location at the same time can be offered individualized prices. Even in the fast-food sector, historically known for its standardization, technology has led to considerably more personalization. McDonald's, for example, has rolled out digital ordering kiosks to personalize menus (freeing former cashiers to greet and serve customers), while its drive-thrus are equipped with $A I$ and license-plate recognition technology allowing instant suggestions based on consumers' past selections, time of day, and weather. Other retailers embrace the opportunities offered by $3 D$ printing to personalize the shopping experience. Ikea, for example, offers a line of 3D-printed add-ons for their furniture, while Dutch supermarket Albert Heijn experimented with customized edible cake decorations.

Fulfilment (aka the last-mile problem) has always been online's Achilles' tendon. Customers have come to expect delivery to be fast and free, often leading to unsustainable costs for the retailer. For Amazon, fulfilment costs already represented $26.5 \%$ of net sales in 2018 , versus $16.5 \%$ in 2008 . Physical stores may come to the rescue, as 
they can act as delivery intermediaries. While many retailers work with serviced pickup-counters, others (e.g., Walmart) focus on automated self-service pickup. In both instances, having the pickup location inside the store has the advantage of stimulating consumers' impulse purchases when picking up the order. Several retailers are currently experimenting with other technologies to crack the last-mile conundrum, among which deliveries with self-driving robots (e.g., www.starship.xyz) and drones (e.g., Google Wing in Canberra, Australia). While these technologies may sound exciting, retailers should realize that in implementing them, they give up the aforementioned touch-point "home-court advantage."

\section{Transaction convenience: self-checkout and no-checkout}

Recent technological advances enable retailers to improve their customers' checkout experience through unmanned checkout-zones or checkoutless stores. The former include automated scan portals (which may be well suited for large grocery baskets) and scanning-on-the-go through mobile devices. Palm Vein Scanning, currently used in selected 7-Eleven stores in Seoul, or the "Smile to Pay" Facial Recognition used by KFC China are just some of the technologies based on biometric authentication that enables no-checkout shopping.

\section{Conclusion}

In spite of the growing success of online retailing, brick-and-mortar stores continue to play a pivotal role in the shopper journey. Technology can be a key enabler to level the playing field, by allowing physical stores to offer the convenience consumers have become used to online.

While numerous business reports have emphasized consumers' increased need for convenience, few marketing studies have paid attention to this evolution. ${ }^{1}$ As such, numerous research opportunities remain wide open. Do beacons and augmented/mixed reality, two technologies that increase search convenience, allow brick-and-mortar retailers to offer a wider product assortment without creating consumer choice deferral? Do technologies that increase possession convenience, such as smart shelf labels and automated self-service pickup, alter consumers' shopping behavior (e.g., their trip frequency, basket sizes, and/or total spending)? Does biometric authentication, which increases transaction convenience, attract new customers, or cause a loss of shoppers due to the apparent privacy invasion?

Also, more work along the lines of Inman and Nikolova's (2017) decision framework that balances innovations' positive and negative consequences for both retailers and shoppers, is needed. Indeed, not all technologies may be equally suited to all consumers, categories, shopping occasions, and retail formats. Unmanned-store technology, for example, makes more sense in settings where salespeople are not expected to upsell consumers, and/or where consumers have low needs for social interaction. In addition, not all convenience dimensions may be equally critical in all settings. A prime

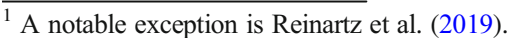


example is the fulfilment issue, which is more critical (and difficult to solve) in grocery retailing than in other retail sectors. Finally, convenience is not the only "new" driver of store renewal that has come to the fore. Apart from a frictionless shopping environment, the store of the future should (ideally) be experiential, serve as a social hub, and focus on curated products. More research is needed on how retailers can strike a balance between all these needs. Interestingly, rather than the USA and Europe, emerging markets (primarily in Asia) are taking the lead in the technology-driven reinvention of the physical store, as these markets are less constrained by existing dominant store bases, are more receptive to alternative payment methods (given a lower credit-card penetration), and have more permissive government policies. Hence, it is more important than ever "to move out of the US/European silo" and conduct more research in those parts of the world that are ahead in consumer-facing technologies.

In sum, while we do not deny that the challenges of automated technology for brickand-mortar retailers are huge, so are the opportunities. At the same time, the uptick in digital initiatives tested by retailers across the world offers countless research opportunities.

Open Access This article is distributed under the terms of the Creative Commons Attribution 4.0 International License (http://creativecommons.org/licenses/by/4.0/), which permits unrestricted use, distribution, and reproduction in any medium, provided you give appropriate credit to the original author(s) and the source, provide a link to the Creative Commons license, and indicate if changes were made.

\section{References}

Business Insider (2019). More than 8,200 stores are closing in 2019 as the retail apocalypse drags on - here's the full list. https://www.businessinsider.com/stores-closing-in-2019-list-2019-3?r=US\&IR=T. Accessed 9 Oct 2019.

Inman, J. J., \& Nikolova, H. (2017). Shopper-facing technology: a retailer adoption decision framework incorporating shopper attitudes and privacy concerns. Journal of Retailing, 93(1), 7-28.

PlanetRetail (2016). Sales assist: the power of mobile instore. Clienteling Technology Report. https://portal. planetretailrng.com/. Accessed 9 Oct 2019.

PlanetRetail RNG (2019). Ecommerce \& digital ecosystem management. https://portal.planetretailrng.com/. Accessed 9 Oct 2019.

Reinartz, W., Wiegand, N., \& Imschloss, M. (2019). The impact of digital transformation of the retailing (value) chain. International Journal of Research in Marketing, 2019.

Seiders, K., Berry, L. L., \& Gresham, L. G. (2000). Attention, retailers! How convenient is your convenience strategy? Sloan Management Review, 41(3), 79-89.

Publisher's note Springer Nature remains neutral with regard to jurisdictional claims in published maps and institutional affiliations. 